\title{
ANALYSIS OF STRENGTH CHANGES OF PLA SAMPLES MADE IN 3D PRINTING TECHNOLOGY
}

\author{
Marcin KWAPISZ, Teresa BAJOR, Marlena KRAKOWIAK \\ Czestochowa University of Technology, Faculty of Production Engineering and Materials Technology, \\ Czestochowa, Poland, EU \\ kwapisz.marcin@wip.pcz.pl, bajor.teresa@wip.pcz.pl, krakowiak.marlena@wip.pcz.pl
}

https://doi.org/10.37904/metal.2019.963

\begin{abstract}
The use of modern technologies, such as 3D printing techniques, creates the possibility of easy and rapid prototyping, being an important element in the design of technological processes. This modern process of elements producing of any shape consists in adding layer by layer of structural material. This is a lossless production, which is an additional advantage compared to conventional technologies such as CNC machining.

The paper presents the results of research on the change in strength of samples made in $3 D$ printing technology in the FDM (Fused Deposition Modeling) technique [1], depending on the method of printing and the percentage filling of the layer. The material used for printing was PLA (polylactide). Flat samples with

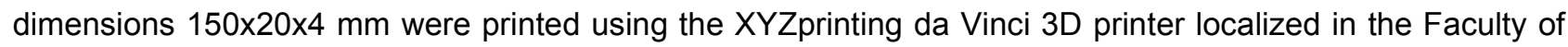
Production Engineering and Materials Technology at the Czestochowa Technical University.

The produced samples were tested in a static tensile test. The research allowed to determine the impact (quantity / method / type) of the filling, and thus the amount of material used and the time of printing, on the strength of tested material. The presented results will enable the selection of optimal printing parameters in order to obtain the expected strength of the parts printed in the FDM technique.
\end{abstract}

Keywords: 3D printing, PLA, strength tests, prototyping, incremental technologies

\section{INTRODUCTION}

The mechanical properties of thermoplastic materials depend on many factors, including: molecular structure, temperature, water content, loading speed and load time. Many of these relationships in metallic materials do not occur or are much weaker. An example of this can be the absorption of water (into the interior of the element) - practically absent in metals thus in plastics sometimes reaching even a few percent in the state of saturation (e.g. in polyamides it is $2.5-7.5 \%$, for PET about $0.8 \%$ ). Absorbed water damages chemical bonds of polymer particles, which causes material degradation manifested by worsen mechanical and physical properties. In steels and other metal alloys contact with water may cause corrosion on the surface, but it is difficult to talk about the absorbability of these materials $[1,2]$.

In recent years, the rapid development of 3D printing technology has been observed. To a large extent, this is related to the increased access to devices, which prices are falling down and they are generally available. 3D printing is an example of an innovative approach to the issues of manufacturing technology. Currently, in every field related to design and production, we can meet the term '3D printing'. Initially, the term concerned only the construction of prototypes. The development of modern technologies has enabled not only the creation of innovative prototypes, but also spare parts with special properties regarding the work parameters. Even whole devices with small dimensions are made in this way. The precision, repeatability and range easy access to 3D printers and consumables, made that unit production is often based on this technology $[3,4,5]$.

Despite the large variety of solutions, realization of 3D printing comes down to the basic principle that is using successive layers of construction material (added layer by layer) $[5,6]$. The most popular 3D printing methods 
are: FDM/FFF (Fused Deposition Modeling/Fused Filament Fabrication), SLA (Stereolithography), SLS (Selective Laser Sintering) i CJP (Color Jet Printing).

Due to the low cost of manufacturing the elements, FDM technology is one of the most commonly used methods of 3D printing. The advantages of this method are [3-6]:

- $\quad$ high strength of prints - there is possibility to partially fill the inside of the printed element with the use of patterns stiffening the structure, which allows to material and printing time saving and enables to obtain light details with high mechanical strength,

- $\quad$ the possibility of subsequent machining (drilling, cutting),

- $\quad$ mapping the properties of the material from which the printout is made,

- resistance to weather conditions,

- repaetability, precision and additive manufacturing.

\section{FDM/FFF (Fused Deposition Modeling / Fused Filament Fabrication) 3D printing technique.}

It consists of adding layers of a material filament extruded through a nozzle, which is heated to a given melting temperature depending on the parameters of the material. The travel direction of the head and the speed of filament extrusion are controlled by software. Applying the next layer occurs by raising the printing nozzle by layer thickness or lowering the work table, it depends on the 3D printer's construction. The general scheme of FDM printing is shown in Figure 1.

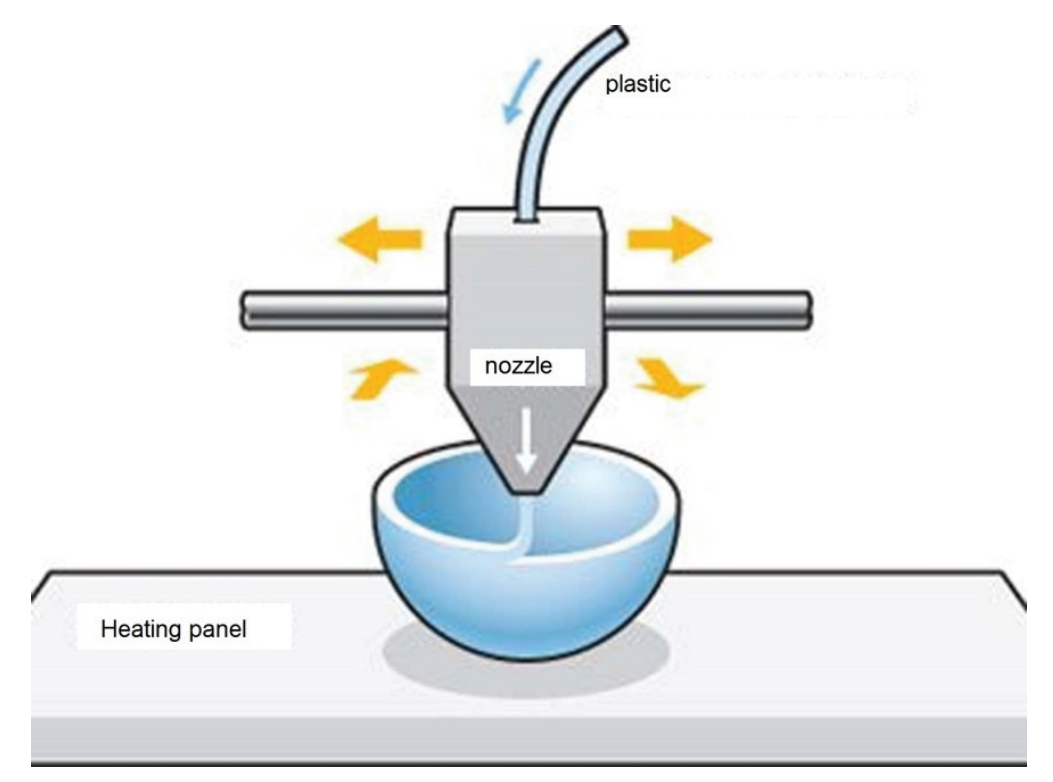

Figure 1 Scheme of FDM printing method [4]

The accuracy of printouts depends on the diameter of the nozzle, the precision of the positioning system, but first of all on the solidification properties of the filament. Due to the methodology of applying layers, printing is mostly done using a single filament. The latest devices implement several head solutions allowing for twocolor printouts, however, due to the cost of the devices are not widely used. Replacing the FDM method is the necessity of placing the printed layer on the foundation because the dissolved filament must have support before it solidifies. Therefore, it is not possible to print items protruding from the surface of the object without additional printing of special supports $[5,7]$.

The most commonly used materials for printing by the FDM/FFF method are: ABS (thermoplastic polymer Acrylonitrile Butadiene Styrene) and PLA (Polylactic Acid or Polylactide). The selection of material depends on the properties that the printed detail should have. 
The aim of the work was to determine the effect of the printing method and density of details prepared by FDM/FFF printing on its mechanical properties. Appropriate selection of process parameters and details dimensions has a significant influence on the course of stress-strain curves.

\section{RESEARCH METHODOLOGY}

For the tests, samples prepared in 3D printing technology in the FDM (Fused Deposition Modeling) technique were prepared, depending on assumed printing method and the percentage density of the layer. The material used to make the samples was PLA (polyactide). Flat samples with dimensions of 150x20x4 mm were printed using the XYZprinting da Vinci 3D printer localized in the Faculty of Production Engineering and Materials Technology at the Czestochowa Technical University.

The conditions and method of tensile testing are described in the PN-EN ISO 527: Plastics. Determination of tensile properties. A typical sample is flat and has a "paddle" shape. The overall shape of the samples is shown in Figure 2 and their dimensions in Table 1.

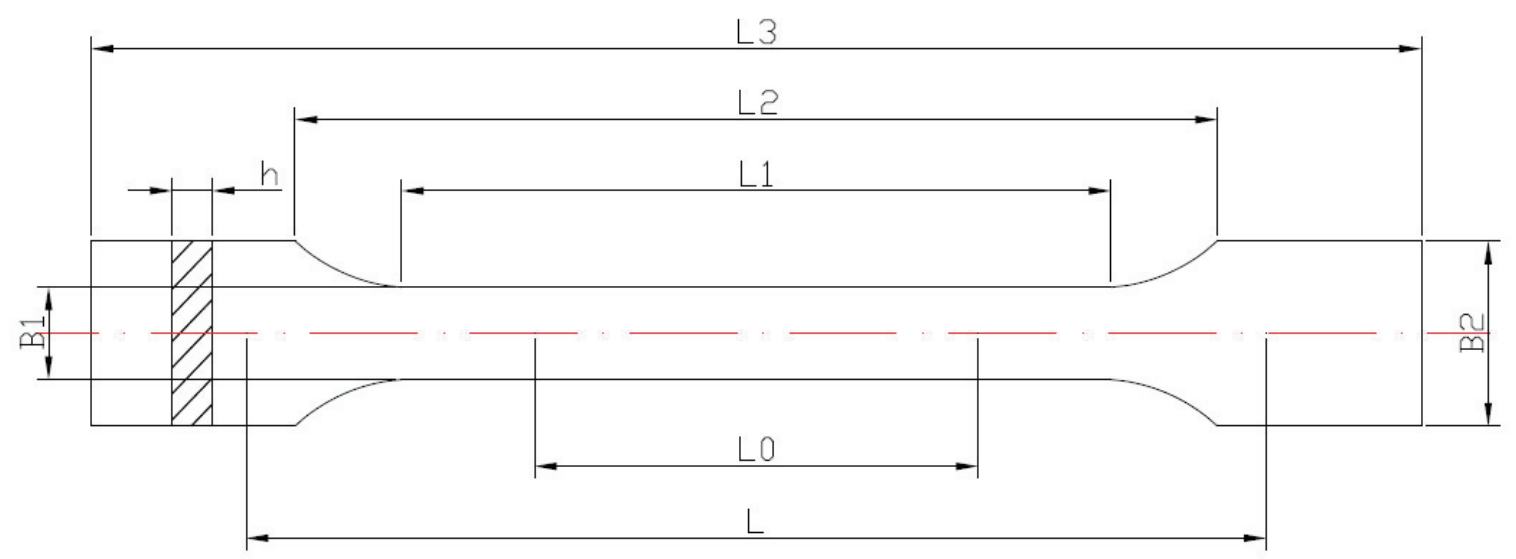

Figure 2 The shape of the test sample [1,5]

Table 1 Dimensions of test samples [1,5]

\begin{tabular}{|l|c|}
\multicolumn{1}{|c|}{ Designation } & Value \\
\hline L3 - total length & $\geq 150 \mathrm{~mm}$ \\
\hline L2 - the distance between the wide parallel situated parts & $104-113 \mathrm{~mm}$ \\
\hline L1 - the length of the part bounded by parallel lines & $80 \pm 2 \mathrm{~mm}$ \\
\hline L0 - measuring length & $50.0 \pm 0.5 \mathrm{~mm}$ \\
\hline L - the initial distance between the grips & $115 \pm 1 \mathrm{~mm}$ \\
\hline R - radius & $20-25 \mathrm{~mm}$ \\
\hline B2 - width at the ends of the sample & $20.0 \pm 0.2 \mathrm{~mm}$ \\
\hline B1 - width of the narrow part of the sample & $10.0 \pm 0.2 \mathrm{~mm}$ \\
\hline H - recommended thickness & $4.0 \pm 0.2 \mathrm{~mm}$ \\
\hline
\end{tabular}

Two types of samples were prepared for the tests: type I - rectilinear printing, type II - honeycomb printing. For each of these types, the density range of the internal layers was changed from 10 to $100 \%$. Three samples were printed for each variant. Figure 3 shows an example of a test set of printed samples. 
The material used for printing was PLA, head temperature was $210{ }^{\circ} \mathrm{C}$ and printing speed $30 \mathrm{~mm} / \mathrm{s}$, layer thickness $0.3 \mathrm{~mm}$, additional layers on the work table in the Raft type.

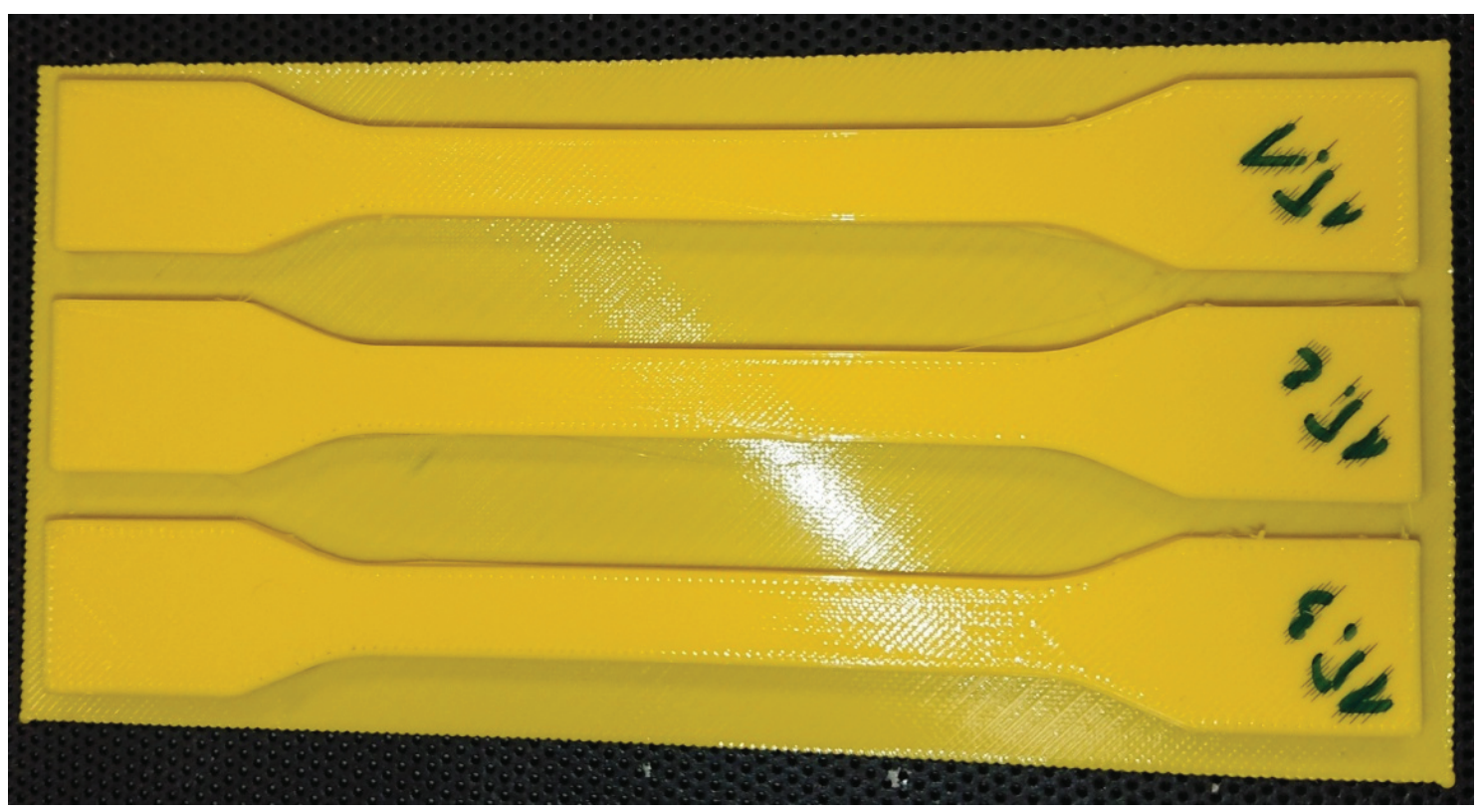

Figure 3 Test set of printed samples

\section{TEST RESULTS}

The printed samples were subjected to a static tensile test on an Instron testing machine - model 5969 (50 $\mathrm{kN})$. The strain rate was $1 \mathrm{~mm} / \mathrm{s}$. Figure 4 presents a diagram of changes in tensile strength $(R \mathrm{~m})$ for two tested printing types depending on the percentage density of internal layers.

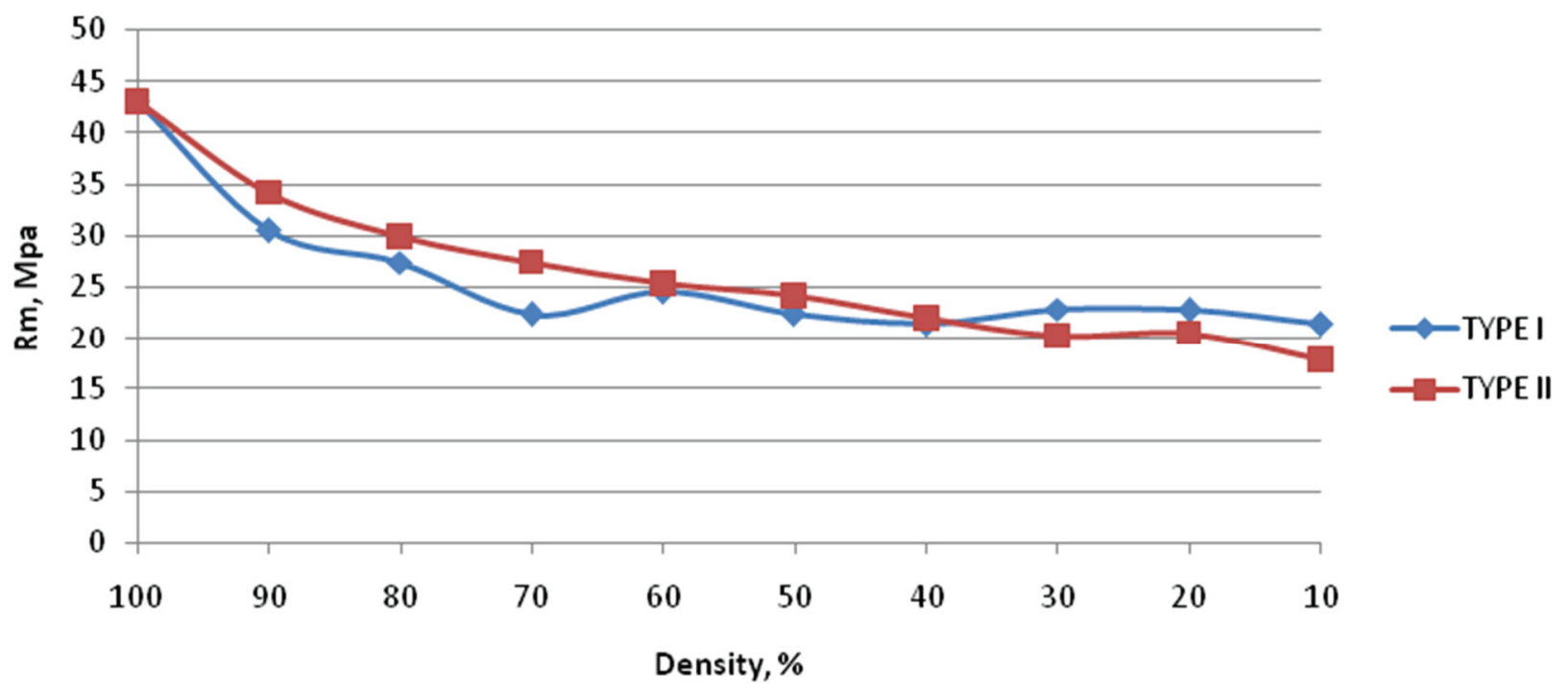

Figure 4 Diagram of changes in tensile strength depending on the percentage density of internal layers

On the basis of the results presented in Figure 4, it can be concluded that decreasing of the percentage density of the layers causes reduction of the value of tensile strength. The proportional decrease in the value of $R m$ along with density reduction in range from 90 to $40 \%$ was observed for the printing of type II. Further reduction 
of density results in higher tensile strengths values for the printing of type I. Figure $\mathbf{5}$ shows a diagram of changes in elongation depending on the percentage density of internal layers for both types of tested samples.

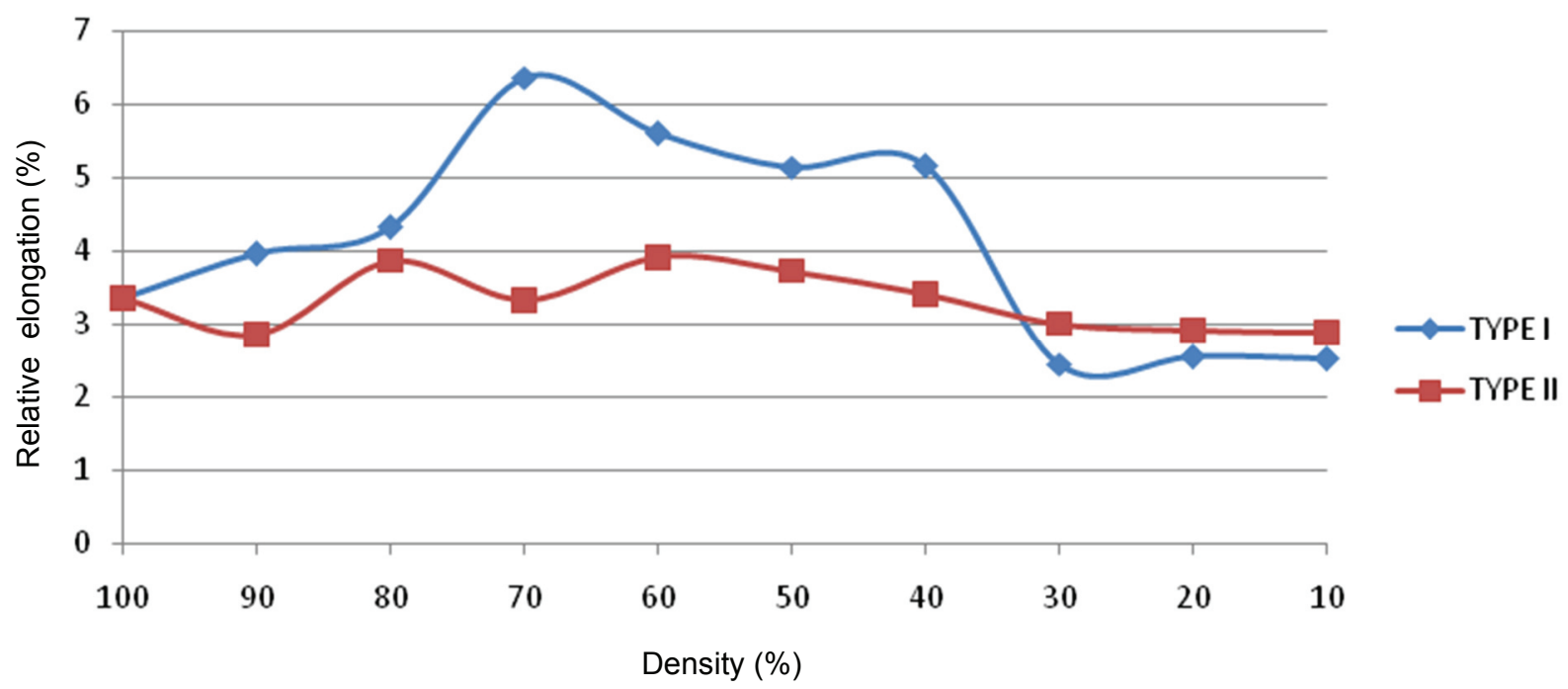

Figure 5 Diagram of changes in elongation depending on the percentage density of internal layers

On the basis of the results presented in Figure 5, it can be concluded that the reduction of density in internal layers of type II samples does not significantly affect for the elongation, while the elongation for the samples of type I in density range of 80 to $40 \%$ is much larger than the results obtained for type II. Table 2 shows the specification of $3 \mathrm{D}$ printing time of the samples depending on the type and percentage density of internal layers.

Table 2 Specification of printing time in dependence on the type and percentage density of internal layers

\begin{tabular}{|c|c|c|}
\hline \multirow{2}{*}{$\begin{array}{c}\text { Density } \\
(\%)\end{array}$} & \multicolumn{2}{|c|}{ time (h:m:s) } \\
\cline { 2 - 3 } & TYPE I - rectilinear & TYPE II - honeycomb \\
\hline $\mathbf{1 0 0}$ & \multicolumn{2}{|c|}{$3: 27: 47$} \\
\hline $\mathbf{9 0}$ & $3: 16: 16$ & $3: 17: 23$ \\
\hline $\mathbf{8 0}$ & $3: 09: 33$ & $3: 12: 12$ \\
\hline $\mathbf{7 0}$ & $3: 02: 45$ & $3: 06: 37$ \\
\hline $\mathbf{6 0}$ & $2: 56: 00$ & $3: 00: 31$ \\
\hline $\mathbf{5 0}$ & $2: 49: 15$ & $2: 53: 18$ \\
\hline $\mathbf{4 0}$ & $2: 42: 44$ & $2: 46: 25$ \\
\hline $\mathbf{3 0}$ & $2: 35: 46$ & $2: 38: 53$ \\
\hline $\mathbf{2 0}$ & $2: 28: 55$ & $2: 31: 01$ \\
\hline $\mathbf{1 0}$ & $2: 22: 06$ & $2: 22: 39$ \\
\hline
\end{tabular}

Based on the data presented in Table 2, it can be stated that there is no clear difference in time of 3D printing between type I and type II. A significant difference in printing time by nearly $50 \%$ occurs between the percentage density of $10 \%$ and $100 \%$. It is obvious that the density of printed layers affects the amount of material used. 


\section{CONCLUSIONS}

The results of research presented in the paper concerned changes in tensile strength and elongation of samples made in 3D printing technology in the FDM technique depending on the type of printing (rectilinear and honeycomb) and percentage density of internal layers. Based on the tests carried out, it can be concluded that:

- $\quad$ reduction in the percentage density of the layers causes a decrease in the tensile strength,

- for Type II (honeycomb) printing, a smaller decrease in tensile strength than for Type I (rectilinear) is observed in the range of layers density from 90 to $40 \%$,

- $\quad$ reducing density of internal layers of Type II (honeycomb) samples does not significantly affect the elongation value achieved,

- elongation of Type I (rectilinear) samples in the range of 80 to $40 \%$ is much larger than results obtained for Type II (honeycomb),

- $\quad$ there is no clear difference in 3D printing time between Type I and Type II,

- the difference in printing time close to $50 \%$ occurs between the percentage density $10 \%$ and $100 \%$.

The presented results will enable the selection of optimal 3D printing parameters in FDM technology in order to achieve the expected strength of printed details.

\section{REFERENCES}

[1] BEŁZOWSKI, A. Degradacja mechaniczna kompozytów polimerowych: Metody oceny wytrzymałości długotrwałej i stopnia uszkodzenia (Mechanical degradation of polymer composites: Methods for assessing long-term durability and degree of damage). Wroclaw: Publishing House. 2002. ISBN 83-7085-630-6. In Polish.

[2] KNOSALA, R. Inżynieria produkcji kompendium wiedzy (Production Engineering. Compendium of Knowledge). Polish Economic Publisher. Warszaw: 2017. In Polish.

[3] KNAPIŃSKI, M. and RAJCZYK, P. Innowacyjne metody modelowania diamentowych narzędzi obróbczych do szlifowania powierzchni kamienia okładzinowego w: Innowacje w Zarządzaniu i Inżynierii Produkcji, red. R. Knosala, Oficyna Wydawnicza Polskiego Towarzystwa Zarządzania Produkcją. (Innovative methods of modeling of diamond tools for grinding the surface of cladding stone). In Innovation in Management and Production Engineering, edited by R. Knosala, Publishing House of PTZP, Opole: 2018. In Polish.

[4] KWAPISZ, M. Charakterystyka Metod druku 3D. (Characteristics of 3D Printing Methods. Management Engineering, Digitization of Production, Research News 1, Warszaw: 2019. In Polish.

[5] MICHTA, D., KACZMARSKA, B., GIERULSKI, W. and SZMIDT, A. Uniwersalność druku 3D w technologii FDM. (Universality of 3D Printing in the FDM Technology), Innovation in Management and Production Engineering. edited by R. Knosala, Publishing House of PTZP, Opole: 2017, vol. 1, pp. 804-814. In Polish.

[6] RAJCZYK, P. and KNAPIŃSKI, M. Examination of diamond grains in segments on metallic binders for granite surface treatment. In METAL 2018: 27th International Conference on Metallurgy and Materials. Ostrava: TANGER Ltd., 2018. pp. 1693-1698.

[7] User Manuals XYZ printing da Vinci 1.0 Pro 3in1 [2019] https://www.xyzprinting.com/support/enUS/Help/tutorial/da\%20Vinci\%201.0\%20Pro\%203in1, data 02.05.2019. 